\title{
BMJ Open Adherence to the Tobacco Control Act, 2007: presence of a workplace policy on tobacco use in bars and restaurants in Nairobi, Kenya
}

\author{
K J Karimi, R Ayah, T Olewe
}

To cite: Karimi KJ, Ayah R, Olewe T. Adherence to the Tobacco Control Act, 2007: presence of a workplace policy on tobacco use in bars and restaurants in Nairobi, Kenya. BMJ Open 2016;6: e012526. doi:10.1136/ bmjopen-2016-012526

- Prepublication history for this paper is available online. To view these files please visit the journal online (http://dx.doi.org/10.1136/ bmjopen-2016-012526).

Received 7 May 2016 Revised 8 July 2016 Accepted 4 August 2016

CrossMark

School of Public Health, University of Nairobi, Nairobi, Kenya

Correspondence to Dr K J Karimi; karimikellen@gmail.com

\section{ABSTRACT}

Introduction: Despite extensive knowledge about effective tobacco control interventions, the prevalence of tobacco use in many middle- and low-income countries continues to rise. In these countries, public appreciation of levels of protection provided by laws and regulations on tobacco use and exposure to tobacco smoke is limited. After ratification of the Framework Convention on Tobacco Control, Kenya enacted the Tobacco Control Act, 2007, banning smoking in public places except in designated smoking areas.

Objective: To assess adherence to the Tobacco Control Act, 2007 by determining the presence of a workplace policy on tobacco use in bars and restaurants.

Methods: A survey of 176 liquor licensed bars and restaurants in Nairobi County was carried out. Their managers were asked about the presence of a workplace policy governing smoking of tobacco, and observations made on provisions that determine adherence to the Tobacco Control Act, 2007.

Results: Smoking took place in almost all bars and restaurants $(150(85 \%))$. Half the establishments $(86$ $(49 \%))$ had a workplace policy governing tobacco use among employees, although a difference between bars $(11(23 \%))$ and restaurants $(75(58 \%))$ was recorded $(p<0.001)$. Establishments at which managers had lower levels of education were less likely to have a workplace policy $(p<0.001)$ and less likely to have 'no smoking' signs and designated smoking areas $(p<0.005)$.

Conclusions and recommendations: Kenya's implementation of the Tobacco Control Act, 2007 does not provide sufficient protection of patrons and workers in bars and restaurants. It is important to sensitise hospitality workers to the dangers of tobacco smoke. Bar and restaurants managers should have a minimum post-secondary education level. The Tobacco Control Act, 2007 requires strengthening to ensure that bars and restaurants have a smoke-free environment.

\section{INTRODUCTION}

Tobacco use is the leading cause of preventable death worldwide. ${ }^{12}$ Risks to health arise

\section{Strengths and limitations of this study}

- This is the first research to be conducted in this geographical area, and could be expanded to other towns and establishments to determine adherence to the Kenyan tobacco policies.

- The study was conducted in a one subcounty in Nairobi County and the results may not be generalisable. This study suggests that more studies in the same geographical area should be conducted.

- A census sampling procedure was used since all the bars and restaurants on the sampling frame were studied.

- Managers and owners of the bars and restaurants were studied and this might have introduced information bias. This was controlled for, however, by collecting data through observation.

- Data were collected in the evening owing to the existing law on alcohol consumption in Kenya. Exposure might have been exaggerated owing to the timing of data collection.

from direct consumption of tobacco and also from exposure to second-hand smoke. ${ }^{2}$ Tobacco is estimated to kill approximately six million people and causes more than half a trillion dollars of economic damage each year. $^{3}$ Exposure to second-hand smoke causes about 600000 deaths in children each year. $^{4}$

The World Health organization (WHO) estimates that unless the Framework Convention on Tobacco Control (FCTC) is fully implemented, as many as one billion people will die in this century. ${ }^{3}$

Smoking prevalence varies widely in sub-Saharan Africa, ranging from $1.8 \%$ in Zambia to $25.8 \%$ in Sierra Leone. ${ }^{5}$ In Kenya, in 2004, the overall prevalence of tobacco smoking was $13.7 \%-26.2 \%$ in men and $1.9 \%$ in women. ${ }^{6}$ The urban prevalence of tobacco smoking in 2013 was estimated to be $13.1 \%$, close to the national average. ${ }^{7}$ 
Protection from exposure to tobacco smoke is mandated in article 8 of the WHO FCTC in all indoor workplaces, public transport and indoor and other public places. ${ }^{8}$ WHO Africa Region recommends that all countries should become compliant with the requirements of article 8 guidelines, and that $100 \%$ smoke-free environments should become the norm in all societies. ${ }^{3}$ Most developed countries have put policies in place towards protection from exposure to second-hand smoke, but an estimated $93 \%$ of the world's population live in countries not fully covered by smoke-free public health regulations. ${ }^{4}$ Specific groups have even greater vulnerability to exposure to tobacco use and second-hand smoke. Among the student population in two of Greece's biggest cities, $86.7 \%$ of the young people had been exposed to passive smoking during the 30 days preceding the survey. Bartenders have been found to have a two- to fourfold greater exposure to second-hand smoke than table waiters. ${ }^{9}$ In addition, workers in bars were found to have a three to fourfold greater risk of lung cancer mortality than those exposed to hazardous worksites. ${ }^{10}$

Kenya became a party to the WHO FCTC on 24 June 2004, making it legally bound by the provisions of the treaty. ${ }^{11}$ As part of their legal obligation Kenya enacted the Tobacco Control Act, 2007, legislation that provides a legal framework for control of tobacco activities, including exposure to second-hand smoke. ${ }^{12}$ However, a 2012 joint national capacity assessment on implementation of effective tobacco control policies in Kenya by WHO established that "there was no clear mechanism that guaranteed smooth and coordinated implementation of the different parts of tobacco control at different levels of governance". ${ }^{11}$ Extensive knowledge about effective interventions exists, but dissemination of tobacco control best practices and adoption and implementation of recommended policies remain patchy. ${ }^{13}$ For example, a significant number of smoke-free workplace policies still do not include hospitality venues such as bars, restaurants and casinos. ${ }^{14}$ This study therefore aimed to determine adherence to the provisions of the Tobacco Control Act, 2007 and establish the presence of a workplace policy in bars and restaurants to enhance protection of workers from exposure to tobacco smoke.

\section{METHODS}

A cross-sectional survey was carried out among bars and restaurants that had a licence to sell liquor in Westlands subcounty; one of the eight administrative subcounties in Nairobi.

Westlands covers an area of $97.6 \mathrm{~km}^{2}$, approximately $14 \%$ of the total area of Nairobi, and has a medium population density living in three divisions-namely, Highridge, Kangemi and Kilimani. ${ }^{15}$

Purposive sampling was employed in the selection of the study area. A sampling frame with the list of all liquor licensed bars and restaurants was obtained from the Westland's subcounty commissioner. A total of 242 liquor licensed bars and restaurants were registered and all were included in the study. Ethical approval was obtained from Kenyatta National Hospital and University of Nairobi ethics and research committee (KNH/UON-ERC P60/02/2012). Administrative clearance was obtained from the Westlands subcounty commissioner's office and the Nairobi City County health department to conduct the study.

The survey was conducted between June and August 2012, with research assistants visiting the bars and restaurants on Friday, Saturday and Sunday, the busy times of the week. Each establishment was visited from 16:00 onwards owing to the existing law on alcohol consumption in Kenya. ${ }^{i}$ For each establishment the manager or owner was identified and written consent obtained. For establishments that were part of a chain in the same region, only one of the establishments was studied to avoid duplication. Managers of the bars and restaurants participating in the study were interviewed and asked about adherence to the provisions of the Tobacco Control Act, 2007 using a structured, pretested questionnaire. In addition, observations were made of the presence of smoking and the existence of workplace policies on tobacco. Variables collected included respondents sociodemographic characteristics, type of establishment (bar or restaurant), presence of people smoking at the establishments, display of "no smoking' signs in the establishments, availability of a designated smoking area and employees entered the smoking areas while smoking was taking place.

\section{Data processing and analysis}

Names of the respondents and bars and restaurants were not used to ensure anonymity and confidentiality. Data collected were checked in the field for errors, corrected by the principal investigators before data entry into software Epi-info 3.5.1 and checked for inconsistencies before exporting to (Statistical Products and Service Solutions) V.17.0 (SPSS) for analysis. Checks for missing values and outliers were made. Univariate analysis was carried out to obtain proportions and means, and the results were tabulated. Bivariate analysis was also carried out to examine possible associations between variables using Pearson's correlation. Simple linear regression was conducted to determine the strength of association, which was considered significant for a $p$ value $\leq 0.05$ (95\% CI).

\section{RESULTS}

Twenty-five establishments were part of a chain and therefore excluded from the study. Of the remaining

\footnotetext{
${ }^{\mathrm{i}}$ Any licensee who keeps his licensed premises open for sale of liquor or sells or displays liquor for sale during any time when he is not authorised by his license to sell, or allows any liquor purchased before the hour of closing to be consumed on such premises after closing hour shall be guilty of an offence. (The Liquor Licensing Act, Cap 121: Part IV-Section 34- Repealed by Alcoholic Control Act, No 4 of 2010.)
} 
217 registered bars and restaurants, a response rate of $81 \%$ was achieved $(n=176)$. Two-thirds $(64 \%)$ of the managers were male, while $36 \%$ were female. About $44 \%(n=77)$ of the respondents had attained at least secondary education; and about half had post-secondary education $(48 \%, \mathrm{n}=84)$.

There were two categories of liquor-licensed establishments: those operating as bars where no food was sold $(27 \%, \mathrm{n}=47)$ and those operating as restaurants where food was sold $(73 \%, n=129)$. Data collected by observation confirmed that smoking was taking place in both types of establishment $(85 \%, \mathrm{n}=150)$. There was no difference in levels of smoking between bars and restaurants. About $49 \%(n=23)$ of bars and $58 \%(n=75)$ of restaurants reported that 'no smoking' signs were displayed in their establishments. In addition, $45 \% \quad(n=21)$ of bars and $62 \%(\mathrm{n}=80)$ of restaurants reported having a designated smoking area.

Almost half $49 \% \quad(n=86)$ of the establishments had some form of workplace policy on tobacco. The presence of a workplace policy was dependent on the type of establishment. A workplace policy was reported among $23 \%(n=11)$ of bars and $58 \%(n=75)$ of restaurants $(\mathrm{p}<0.001)$. A $\chi^{2}$ test was conducted and significant association was found between the managers' level of education and presence of a workplace policy on tobacco use $(p<0.001)$. The higher the level of education of the manager the greater was the likelihood of the establishment having a workplace policy $(\mathrm{p}<0.001)$ (table 1). A further correlation was found between the managers' level of education and the presence of designated smoking areas as well as display of 'No smoking' signs $(\mathrm{p}<0.05)$.

However, no relationship was found between the managers' level of education and whether smoking was taking place in the establishments $(\mathrm{p}>0.01)$.

\section{DISCUSSION}

This study sought to determine implementation of the Tobacco Control Act, 2007, especially adherence to the provisions that protect against exposure of non-smokers to tobacco smoke, and to establish availability of a workplace policy on tobacco use in the bars and restaurants. Adherence to the provisions was not strict, implying exposure to tobacco smoke among patrons and workers of the bars and restaurants.
Tobacco smoking was seen in $86 \%$ of bars and restaurants. This finding is not unusual as Kenya's smoke-free law does not fully meet the FCTC requirements allowing for specially designated smoking areas. ${ }^{16}$ In a 2007 survey, smoking was observed in $77.5 \%$ of 404 restaurants and bars in five cities across China despite the country having ratified the FCTC in $2005 .{ }^{17}$ In Chile a partial smoking ban legislation enacted in 2007 provided no protection to employees working in bars and restaurants. Air nicotine concentrations were found to be 3.2, 35.5 and 56.2 times higher in non-smoking areas in mixed venues, smoking areas in mixed venues and smoking venues, respectively, than in smoke-free venues. ${ }^{18}$ A study in Tunisia on global air monitoring compared levels of indoor air pollution in different workplaces and found that hospitality venues allowing indoor smoking were more polluted $(85 \%)$ than both indoor smoke-free sites and outdoor air. ${ }^{19}$ An assessment of nicotine concentrations in restaurants and bars in Guatemala, found them to be as much as 710 times higher than equivalent spaces in Guatemalan public schools; designated non-smoking areas were largely useless. $^{20}$ Exposure to second-hand smoke was highly prevalent and workers in bars and restaurants were more exposed than other workers, therefore necessitating urgent need for complete implementation of smoke-free policies and educating workers about the benefits of smoke-free workplaces. ${ }^{21}$

Second-hand smoke remains an important occupational hazard for non-smoking and smoking employees in the workplace. An assessment of exposure of bar and nightclub employees to second-hand smoke found that a twofold increase in air nicotine concentrations was associated with a $30 \%(95 \%$ CI $23 \%$ to $38 \%)$ increase in hair nicotine concentrations in non-smoking employees. $^{22}$ In our study, smoking occurred whether or not there were 'no smoking signs'. This might have been partly because the power to enforce 'no smoking' regulations was left to individual managers who ended up being conflicted between the law and their customers' wishes. These managers would prefer to forfeit their local discretion and for the workplace smoking ban in bars and restaurants to be implemented by a government agency. ${ }^{23}$ Additionally, the level of education of the managers of the bars and restaurants was a key determinant of the presence of a workplace policy in their premises. Nationally, half of all Kenyan men (49\%)

Table 1 Presence of workplace policy on tobacco

\begin{tabular}{|c|c|c|c|c|c|c|}
\hline \multirow[b]{2}{*}{ Variable } & & \multirow[b]{2}{*}{ Classification } & \multirow[b]{2}{*}{ Frequency (\%) } & \multicolumn{3}{|c|}{ Presence of workplace policy } \\
\hline & & & & Yes (n) (\%) & No (n) (\%) & p Value \\
\hline \multirow[t]{3}{*}{ Level 1} & Sociodemographic characteristics & Primary & $15(8.5)$ & $0(0)$ & $15(100)$ & $<0.001$ \\
\hline & (level of education) & Secondary & $77(43.8)$ & $34(44.2)$ & $43(55.8)$ & \\
\hline & & Tertiary & $84(47.7)$ & 52 (61.9) & $32(38.1)$ & \\
\hline \multirow[t]{2}{*}{ Level 2} & Type of establishment & Bar & $47(27)$ & $11(23.4)$ & $36(76.6)$ & $<0.001$ \\
\hline & & Restaurant & $129(73)$ & $75(58.1)$ & $54(41.9)$ & \\
\hline
\end{tabular}


have at least a secondary or higher level of education; our sample therefore mirrored the national figures. ${ }^{15}$ One of the key interventions in reducing tobacco use is through educational programmes in schools. ${ }^{24}$ In Guatemala it was observed that years after the enactment of a tobacco control law owners/managers and employees of bars and restaurants claimed not to be familiar with the law and, consequently, long-term compliance with the smoking ban in Guatemala was decreasing. ${ }^{25}$ Part of the solution to the problem of tobacco use, therefore, lies outside the industry. In their study, Borland $e t a l^{26}$ concluded that support for smoking bans was associated with living in places where smoking was prohibited, suggesting the effectiveness of policies in reducing smoking levels, and therefore reduced exposure to tobacco smoke among non-smokers.

Thrasher $e t a l^{27}$ conducted another study on tobacco smoke exposure in public places and workplaces after smoke-free policy implementation among smoker cohorts in Mexico and Uruguay. Initially, workplace second-hand smoke exposure was similar within and across the two countries (range: Mexico 20-25\%; Uruguay 14-29\%). Comprehensive smoke-free policies were implemented, leading to reduction in exposure (Uruguay 6-9\%; Mexico 5-7\%). Exposure remained high in jurisdictions with weaker policies. The study concluded that comprehensive smoke-free policies are more effective than weaker policies. ${ }^{27}$

A study by Fong et $a l,{ }^{28}$ on Ireland's smoke-free law is an example of how a population-level policy intervention can achieve public health goals. Findings from the study show support of the implementation of smoke-free legislation, especially by countries that have ratified the FCTC that call for reduction of tobacco smoke pollution. Studies on the level of education of people required to ensure implementation of smoke-free policies are not available, even in countries that have successfully implemented the laws.

About half of Kenya's population is aged $<25$ years, a structure not expected to change much for the next 30 years. This youthful population remains vulnerable to the dangers of tobacco, including second-hand smoke. This study describes the public health importance of protecting workers of bars and restaurants from harmful effects arising from exposure to second-hand smoke.

\section{Study limitation}

One limitation was the process of obtaining consent from the respondents since most of those who declined to take part in the study were owners and managers of member clubs and entities that were not open to the public. Exposure in these establishments might have been greater than in the bars and restaurants we studied.

Timing of the data collection might have introduced bias as we visited the establishments during peak hours during the last days of the week, when the bars and restaurants were busiest.

\section{CONCLUSION AND RECOMIMENDATION}

Adherence to the provisions of the Tobacco Control Act, 2007, was partial. There were also reports of the absence of a workplace policy on tobacco use, mostly in establishments operating as bars. Tobacco smoke, including second-hand smoke, is one of the leading risk factors for the global burden of disease. ${ }^{29}$ Comprehensive smokefree regulations are the most effective strategy for reducing tobacco use and second-hand smoke exposure. More education is needed on the public health importance of protection from exposure to tobacco smoke. The government should strengthen the tobacco act to ensure that bars and restaurants are smoke free. Managers of bars and restaurants should have a minimum qualification of post-secondary education.

Twitter Follow Kellen Karimi at @karimikellen

Contributors KJK, RA: conceived the study, participated in the design, performed the statistical analysis and drafted the manuscript. T0: conceived the study and participated in the design. All authors read and approved the final manuscript.

Funding This research received no specific grant from any funding agency in the public, commercial or not-for-profit sectors.

Competing interests None declared.

Ethics approval Ethical approval for this study was obtained from the Kenyatta National Hospital and University of Nairobi ethics research committee (KNH/UON-ERC P60/02/2012).

Provenance and peer review Not commissioned; externally peer reviewed.

Data sharing statement Additional data can be accessed via the Dryad data repository at http://datadryad.org/ with the doi:10.5061/dryad.sj3mp

Open Access This is an Open Access article distributed in accordance with the Creative Commons Attribution Non Commercial (CC BY-NC 4.0) license, which permits others to distribute, remix, adapt, build upon this work noncommercially, and license their derivative works on different terms, provided the original work is properly cited and the use is non-commercial. See: http:// creativecommons.org/licenses/by-nc/4.0/

\section{REFERENCES}

1. World Health Organization. Mortality attributable to tobacco: WHO Global Report. WHO Library Cataloguing-in-Publication Data, 2012:4.

2. World Health Organization. Global status report on noncommunicable diseases 2014. World Health Organization, 2014:176. http://doi.org/ISBN9789241564854

3. World Health Organization. WHO Report on the Global Tobacco Epidemic. WHO Report on the Global Tobacco Epidemic, Vol 5, 2013:106. http://doi.org/10.1002/aehe.3640230702

4. Öberg M, Jaakkola MS, Woodward A, et al. Worldwide burden of disease from exposure to second-hand smoke: a retrospective analysis of data from 192 countries. Lancet 2011;377:139-46. http:// doi.org/10.1016/S0140-6736(10)61388-8

5. Brathwaite R, Addo J, Smeeth L, et al. A systematic review of tobacco smoking prevalence and description of tobacco control strategies in sub-Saharan African countries; 2007 to 2014. PLoS ONE 2015;10:e0132401.

6. World Health Organization. WHO Report on the Global Tobacco Epidemic 2008 The MPOWER package. WHO Library Cataloguing-in-Publication Data, 2008:330. http://www.who.int/ tobacco/mpower/mpower_report_full_2008.pdf

7. Ayah R, Joshi MD, Wanjiru R, et al. A population-based survey of prevalence of diabetes and correlates in an urban slum community in Nairobi, Kenya. BMC Public Health 2013;13:371. http://doi.org/10. 1186/1471-2458-13-371

8. Lin V. The Framework Convention on Tobacco Control and health promotion: strengthening the ties. Glob Health Promot 2003;17(1 Suppl):76-80. http://doi.org/10.1177/1757975909358365 
9. Maskarinec MP, Jenkins RA, Counts RW, et al. Determination of exposure to environmental tobacco smoke in restaurant and tavern workers in one US city. J Expos Anal Environ Epidemiol 2000;10:36-49.

10. Siegel M, Skeer M. Exposure to secondhand smoke and excess lung cancer mortality risk among workers in the " 5 B's": bars, bowling alleys, billiard halls, betting establishments, and bingo parlours. Tob Control 2003;12:333-8. http://doi.org/10.1136/tc.12.3. 333

11. World Health Organization. Joint National Capacity Assessment on the implementation of effective tobacco control policies in Kenya. Geneva: WHO Library Cataloguing-in-Publication Data, 2012.

12. The Republic of Kenya. Tobacco Control Act. Kenya: National Council for Law Reporting, 2012.

13. Davis RM, Wakefield M, Amos A, et al. The Hitchhiker's Guide to Tobacco Control: a global assessment of harms, remedies, and controversies. Annu Rev Public Health 2007;28:171-94. http://doi. org/10.1146/annurev.publhealth.28.021406.144033

14. Jensen JA, Schillo BA, Moilanen MM, et al. Tobacco smoke exposure in nonsmoking hospitality workers before and after a state smoking ban. Cancer Epidemiol Biomarkers Prev 2010;19:1016-21. http://doi.org/10.1158/1055-9965.EPI-09-0969

15. National Bureau of Statistics-Kenya and ICF International. Kenya 2014 DHS Key Findings. 2015. https://www.dhsprogram.com/pubs/ pdf/SR227/SR227.pdf.

16. Tumwine J. Implementation of the Framework Convention on Tobacco Control in Africa: current status of legislation. Int $J$ Environ Res Public Health 2011;8:4312-31. http://doi.org/10.3390/ ijerph8114312

17. Liu R, Yang Y, Travers M, et al. A cross-sectional study on levels of secondhand smoke in restaurants and bars in five cities in China. Tob Control 2011;20:397-402.

18. Erazo M, Iglesias V, Droppelmann A, et al. Secondhand tobacco smoke in bars and restaurants in Santiago, Chile: evaluation of partial smoking ban legislation in public places. Tob Control 2010;19:469-74. http://doi.org/10.1136/tc.2009.035402

19. Koong HN, Khoo D, Higbee C, et al. Global air monitoring study: a multi-country comparison of levels of indoor air pollution in different workplaces. Ann Acad Med Singapore 2009;38:202-6.

20. Fundación Aldo Castaneda. 2006. http://www.idrc.ca/tobacco/ ev-140615-201-1-DO_TOPIC.htm
21. Joaquin B, Monzon JC, Briz P, et al. Compliance to the smoke-free law in Guatemala 5-years after implementation. BMC Public Health 2016;16:1-5. http://doi.org/10.1186/s12889-016-2960-x

22. Jones MR, Wipfli H, Shahrir S, et al. Secondhand tobacco smoke: an occupational hazard for smoking and non-smoking bar and nightclub employees. Tob Control 2013;22:308-14. http://doi.org/10. 1136/tobaccocontrol-2011-050203

23. Montini T, Bero LA. Implementation of a workplace smoking ban in bars: the limits of local discretion. BMC Public Health 2008;8:402. http://doi.org/10.1186/1471-2458-8-402

24. Mendis S. The policy agenda for prevention and control of non-communicable diseases. Br Med Bull 2010;96:23-43. http://doi. org $/ 10.1093 / \mathrm{bmb} / \mathrm{ldq037}$

25. Barnoya J, Mendoza-Montano C, Navas-Acien A. Secondhand smoke exposure in public places in Guatemala: comparison with other Latin American countries. Cancer Epidemiol Biomarkers Prev 2007;16:2730-5. http://doi.org/10.1158/1055-9965.EPI-07-0229

26. Borland $\mathrm{R}$, Yong $\mathrm{HH}$, Siahpush $\mathrm{M}$, et al. Support for and reported compliance with smoke-free restaurants and bars by smokers in four countries: findings from the International Tobacco Control (ITC) Four Country Survey. Tob Control 2006;15(Suppl 3):iii34-41. http://www. pubmedcentral.nih.gov/articlerender.fcgi?artid $=2593054 \&$ tool $=$ pmcentrez\&rendertype $=$ abstract

27. Thrasher JF, Nayeli Abad-Vivero E, Sebrié EM, et al. Tobacco smoke exposure in public places and workplaces after smoke-free policy implementation: a longitudinal analysis of smoker cohorts in Mexico and Uruguay. Health Policy Plan 2013;28:789-98. http://doi. org/10.1093/heapol/czs118

28. Fong GT, Hyland A, Borland R, et al. Reductions in tobacco smoke pollution and increases in support for smoke-free public places following the implementation of comprehensive smoke-free workplace legislation in the Republic of Ireland: findings from the ITC Ireland/UK Survey. Tob Control 2006;15(Suppl 3):iii51-8. http://www. pubmedcentral. .nih.gov/articlerender.fcgi?artid=2593063\&tool= pmcentrez\&rendertype $=$ abstract

29. Murray CJL, Vos T, Lozano R, et al. Disability-adjusted life years (DALYs) for 291 diseases and injuries in 21 regions, 1990-2010: a systematic analysis for the Global Burden of Disease Study 2010. Lancet 2012;380:2197-223. http://doi.org/10.1016/S0140-6736(12) $61689-4$ 